\title{
LA DIVERSIDAD CULTURAL OAXAQUEÑA A LA LUZ DE LA ÉTICA AMBIENTAL
}

\author{
Oaxaca's Cultural Diversity in the Light of Environmental Ethics \\ José María Filgueiras-Nodar
}

Resumen: En este artículo se trata de poner en relación algunos aspectos de las cosmovisiones de diferentes pueblos originarios del estado de Oaxaca (México) con ciertos intereses de la ética ambiental contemporánea, como las perspectivas del pragmatismo ambiental y la ética ambiental comparada. Así, se mostrarán dos elementos presentes en las cosmovisiones de diferentes etnias oaxaqueñas que resultan relevantes para la ética ambiental, como son la existencia de deidades ligadas a la protección ambiental, y también algunas ideas sobre el lugar que el ser humano ocupa en el mundo.

Palabras clave: cosmovisión indígena, medioambiente natural, ética ambiental.

Abstract: This article attempts to relate some aspects of the world views of different native peoples of Oaxaca State (Mexico) with certain interests of contemporary environmental ethics, from the perspectives of environmental pragmatism and comparative environmental ethics. It will demonstrate that two elements displayed in the worldviews of several Oaxacan ethnicities are relevant for environmental ethics, these being the existence of deities linked to environmental protection and ideas about the place that human beings occupy in the world.

Keywords: cosmovision of original peoples, natural environment, environmental ethics.

José María Filgueiras Nodar, doctor en Filosofía Contemporánea por la Universidad Autónoma del Estado de Morelos, Cuernavaca, México. Profesor-investigador en el Instituto de la Comunicación, Universidad del Mar, Campus Huatulco, México. Temas de especialización: ética ambiental, pragmatismo. Correo electrónico: jofilg@huatulco.umar.mx, metralatam@hotmail.com.
Enviado a dictamen: 14 de abril de 2015.

Aprobación: 7 de septiembre de 2015.

Revisiones: 1 . 
Introducción: entre el pragmatismo ambiental y la ética ambiental comparada

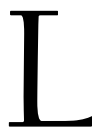
a tesis que defenderé en este artículo es que la observación de las cosmovisiones y las prácticas sociales de las etnias originarias del estado de Oaxaca puede ofrecer interesantes lecciones a la ética ambiental contemporánea. Una tesis que, para ser contextualizada cabalmente, requiere de la presentación somera de dos concepciones de la actual ética ambiental, así como de algunos comentarios sobre las relaciones entre ambas. La primera de tales concepciones es el "pragmatismo ambiental" (Light y Katz, 1996a y 1996b; Light, 2003; Light y McKenna, 2004), cuya concepción básica es que los filósofos ambientales han pasado demasiado tiempo discutiendo asuntos teóricos - especialmente la cuestión del "valor intrínseco"-, sin que estas disquisiciones hayan generado demasiados resultados prácticos. Partiendo de esta intuición de fondo, los pragmatistas ambientales, luego de declarar su agnosticismo ante la cuestión del valor intrínseco (Light, 2003: 25l), definen su actitud como la "investigación abierta sobre los problemas específicos, en situaciones reales, de la relación entre la humanidad y el ambiente" (Light y Katz, 1996: 2), y la consideran capaz, por ello, de generar aportaciones útiles para enfrentar la actual crisis ambiental.

Para entender cuáles pueden ser específicamente estas aportaciones del pragmatismo ambiental, quisiera recordar las reflexiones de Light y McKenna (2004: 9-11) que, aun refiriéndose a un ángulo más limitado de la ética ambiental, parecen aplicables al conjunto de la disciplina. Uno de los aspectos destacados por estos autores es que el pragmatismo es heredero de un legado de intervención por parte de los filósofos en los asuntos públicos - pensemos, por ejemplo, en Dewey-, lo cual facilita e incluso puede presionar a los estudiosos del pragmatismo para que traten temas de relevancia actual, como la crisis ecológica, y a tratarlos no como un tema "de salón", sino con cierto nivel de compromiso. Otro aspecto es que la aversión del pragmatismo por las dicotomías excluyentes le ha conducido a desarrollar una metodología capaz de integrar elementos deliberadamente separados por otros enfoques teoría/práctica, razón/emoción, etcétera-. El tercer elemento mencionado es que el pragmatismo, más que proporcionar principios inamovibles — sean éticos o epistemológicos- que guíen nuestra acción, trata de desarrollar una actitud crítica ante los propios hábitos, de forma que puedan ser modificados con base en las experiencias que se van teniendo. Tal experimentalismo le da una ventaja a la ética ambiental ante las aproximaciones principialistas, ya que le permite adaptarse a las circunstancias de un modo mucho más rápido.

Estas consideraciones parecerían constituir ventajas del pragmatismo ambiental a la hora de generar sus aportaciones, las cuales en última instancia tienen que ver con la búsqueda de las maneras más adecuadas de influir sobre las conciencias. Semejante tarea, afirman Light y Katz (1996: 5), puede llevarse a cabo de cuatro formas fundamentales, siendo una de ellas el desarrollar argumentos a favor del pluralismo moral en cuestiones ambientales.

En referencia a esta búsqueda de argumentos que apoyen el pluralismo, quisiera introducir la segunda concepción que apuntala la tesis principal de este artículo: la "ética ambiental comparada", propuesta inicialmente por Callicott (1994). Este autor arranca con un análisis histórico de la crisis ambiental, así como de las reacciones suscitadas por la misma, especialmente después de la publicación en 1962 de Primavera silenciosa, de Carson (2010), y, siendo filósofo, se pregunta qué pueden hacer los filósofos para ayudar ante dicha crisis. La tarea de otros estudiosos, como sociólogos o economistas, se le aparece bastante más claramente, pues estos serían los encargados de analizar de manera empírica las bases de la crisis, identificando así numerosos elementos estructurales que deben ser modificados. No obstante, las modificaciones requeridas pasan casi siempre por el comportamiento individual, el cual exige la aceptación sincera de una serie de valores relativos al medioambiente. Ahora bien, para que una persona acepte plenamente tales valores, 
éstos deberían hallarse lo más en consonancia que sea posible con sus puntos de vista morales, puesto que el ser humano tiende a aceptar más fácilmente aquellas novedades que no se contraponen de manera directa con su sistema previo de creencias. Por ejemplo: la conocida concepción del stewardship en ética ambiental resulta mucho más fácil de admitir para una persona cristiana que, pongamos por caso, para una taoísta (ver, por ejemplo, Glacken, 1967).

Dado que la crisis ambiental es una amenaza global, que además pone en riesgo la supervivencia de toda la especie, es de suponer también que para enfrentar esta amenaza se requerirá no de una sola ética ambiental, sino de una pluralidad de propuestas. Propuestas que deberán estar en sintonía con los puntos de vista particulares de diferentes culturas. Este reconocimiento de la necesidad del pluralismo conecta de manera muy sólida la ética ambiental comparada con el pragmatismo ambiental.

Por supuesto, debe tenerse en cuenta también, como afirma Rozzi, que "no toda la especie humana está en conflicto con la biodiversidad" (2001: 282), pues existen sociedades que viven en relativa armonía con su entorno biofísico. Tanto desde la perspectiva de la ética ambiental comparada como del pragmatismo ambiental resulta legítimo investigar esas sociedades y sus configuraciones culturales para tratar de extraer las lecciones más relevantes a la hora de enfrentar la crisis ambiental en que Occidente ha sumido al planeta. La urgencia de responder a la crisis exige tal búsqueda. Al mismo tiempo, el caso así establecido a favor del pluralismo aporta razones para rescatar y defender las cosmovisiones de los pueblos originarios, en busca de elementos capaces de aportar nuevas ideas para esa "conversación de la cultura" de que hablaba, entre otros, Richard Rorty, conversación que corre el riesgo de acabar súbitamente a causa de un colapso ambiental. Buscar esta clase de concepciones en las etnias oaxaqueñas es precisamente el objetivo de este trabajo. En el siguiente apartado trataré de sugerir un par de elementos que me parecen relevantes para cumplir con tal objetivo.

\section{Dioses "ecologistas" para un ser humano inseparable del resto de la naturaleza}

Oaxaca es el estado de la República Mexicana con un mayor número de pueblos originarios, al albergar en su territorio a quince grupos etnolingüísticos, ${ }^{2}$ además de otro grupo, los afromestizos, que, aun sin haber obtenido un reconocimiento legislativo como pueblo originario, comparte muchos aspectos con los mismos (GEO, 201l: 277). Todos estos pueblos contribuyen al establecimiento de una ingente diversidad cultural que, como decía, sugiere ideas muy interesantes para la ética ambiental. De entre las muchas existentes, para este artículo he seleccionado únicamente dos concepciones, que serán tratadas en los siguientes epígrafes: la existencia de deidades ligadas a la protección ambiental, y las concepciones sobre el lugar que el ser humano ocupa en el mundo. Desde luego, quedarán fuera muchos otros temas igualmente interesantes, como la sacralización del espacio y su vinculación ritual con fuerzas naturales, la divinización de muchos elementos naturales o las concepciones que sobre la salud defienden estos pueblos, pero creo que el carácter exploratorio del artículo justifica esta exclusión.

\section{Deidades ligadas a la protección ambiental}

Comenzaré, entonces, refiriéndome a la existencia en las cosmovisiones de las etnias originarias oaxaqueñas de deidades o seres sagrados que se dedican a la conservación o protección de determinados elementos naturales. Al respecto, una figura especialmente interesante es la del Señor de los Animales, que aparece con diversos nombres en varias etnias oaxaqueñas y que se encarga de proteger a determinados animales de su caza excesiva. Entre los huaves - conocidos también como mareños-, un grupo cuya principal actividad económica es la pesca, existe el Rey de los Camarones, "un camarón grandísimo que se come a la gente que no respeta las fiestas y entra en el mar cuando es fecha delicada" (Brockmann, 2004 98). Este camarón, en efecto, aparece en momentos destacados del calendario ritual huave, como las fiestas de la Virgen de la Candelaria y San Mateo, y de forma muy 
destacada en Semana Santa, una época "especialmente peligrosa [porque] Dios se está muriendo y no puede estar pendiente de sus hijos" (Brockmann, 2004: 98). Según este mismo autor, los huaves reconocen también una dueña de los pescados y de las tortugas: la sirena.

Los chinantecos, por su parte, hablan de un Dueño de los Animales (Fii jo'nuun), que siempre suele ser fácilmente identificable como el animal más fuerte o grande del grupo. Este Dueño marca las orejas de animales como los jabalíes o los coyotes para mostrar que son de su propiedad, y trata de desorientar a los cazadores cuando quieren cobrar sus piezas (Bartolomé et al., 1999). Para los cuicatecos, el 'Ivi iti o Dueño de los Animales no sólo protege a éstos de los cazadores que llegan de otros pueblos, sino que "les da la misión de ser mensajeros; por ejemplo, el búho trae malos augurios y la zorra indica la cercanía de la lluvia" (Lizama, 1999: 306). La cosmovisión de los mixtecos, por su parte, conserva algunos elementos de su antigua religión politeísta, que han sobrevivido al impacto del cristianismo. Así, "todavía recuerdan a algunas de sus deidades tutelares, consideradas dueños, patrones o señores de cada lugar, a quienes piden permiso para cazar [...] o realizar cualquier actividad que suponga una apropiación o transformación de algún elemento de la naturaleza" (Mindek, 2003: 10). Los mixes, hábiles cazadores, también piden permiso al Dueño de los Animales a través de rituales realizados antes de salir a cazar, especialmente en las noches en que no hay luna (Torres, 2004: 16).

En su estudio de los chatinos, Bartolomé y Barabás definen a los Dueños de los Animales (Ho'o X'na $\mathrm{Na}$ 'Ni) como los "encargados de los animales salvajes, regulando tanto su reproducción como las relaciones de caza prescriptas para los hombres" (1996: 214). Vistos frecuentemente en las experiencias alucinógenas, se describen como personas de vestimenta occidental con grandes zapatos y sombreros, que se muestran siempre de espaldas o de perfil, jamás de frente. Bartolomé y Barabás señalan que:

[...] en el Cerro Peñasco Agrio reside uno que posee un gran rancho, donde viven todos los animales del área que están a su cuidado. A los que cazan demasiado o no cumplen con las reglas de repartir la caza con sus familiares, los retiene en el monte como sirvientes [...] Por ello hay que pedirle permiso antes de salir a cazar, encendiéndole una vela y ofreciéndole panes, atole, etcétera, a fin de retribuirle por el permiso acordado (Bartolomé y Barabás, 1996: 214-215).

Unas reflexiones de Bartolomé y Barabás inciden directamente sobre la problemática de la ética ambiental:

El concepto de Señor de los Animales parte de una noción presente en el pensamiento chatino; la posibilidad de comunicarse con el medio ambiente que los rodea estableciendo un tipo de relación social equilibrada, en los mismos términos que rigen idealmente las relaciones sociales humanas [...] Los Señores de los Animales carecen de los atributos de deidades creadoras, pero sí se desempeñan como deidades protectoras que legalizan las relaciones transaccionales que el hombre establece con el reino animal, del cual él mismo forma parte. Relación que se evidencia tanto en la noción del Alter Ego animal como en la presencia de estas deidades reguladoras de la caza, cuya existencia expresa un tipo de racionalidad socio-ecológica (Bartolomé y Barabás, 1996: 215).

Para profundizar en el sentido de tal racionalidad, debe tenerse en cuenta que, cuando Bartolomé y Barabás visitan el área chatina, constatan que la caza se ha convertido en una actividad secundaria, mientras que "veinte años atrás [...] era un importante complemento de la dieta" (1996: 342). Esta transformación, afirman, se debió a las alteraciones del hábitat por parte de las compañías madereras, así como a la contaminación de las aguas, pero en ningún caso a los chatinos:

[...] la razón central que les impide extralimitarse en la cacería es la existencia de normas sagradas y sociales que regulan la frecuencia de la caza y la repartición de las presas respectivamente. Por el mismo acto de cazar se establece una relación muy estrecha entre 
los hombres y la entidad tutelar de los animales [...], relación de intercambio recíproco en la que el hombre debe ofrecer y cumplir determinados requisitos para que la deidad le entregue lo que pide (Bartolomé y Barabás, 1996: 343).

Estos autores señalan también algunos de tales requisitos: no se puede salir a buscar animales - generalmente venados - hasta que alguien ve las huellas de dichos animales, considerándose entonces que es el Dueño el que ha decidido mostrar el animal. Una vez alguien ve las huellas, se reúne un grupo de cuatro o cinco hombres, con perros y escopetas, para cazar el venado. Antes de cazar, es necesario que el grupo pida permiso al Dueño de los Animales, ofreciéndole alimentos, con la finalidad de mostrar las buenas intenciones de los cazadores. Ya de cacería, el que mata al animal debe repartirlo entre los compañeros, reservando para su madre, su esposa y su madrina las vísceras y la cabeza del mismo; cuando se trata de un venado, debe limpiar cuidadosamente los huesos, guardándolos de los perros y otros animales. Una importante norma es que "la carne debe destinarse exclusivamente para el consumo doméstico, ya que al que caza para vender, el Dueño de los Animales le "quita la suerte"” (Bartolomé y Barabás, 1996: 344).

¿Qué sucede cuando tales requisitos no se cumplen? Un relato recogido por Bartolomé y Barabás cuenta que un Dueño de los Venados se llevó a una mujer que no compartía la carne con su marido, sino que se la daba a su amante, y por ello hizo que los venados se comieran a la mujer. Como afirman los autores, en este caso:

[...] no sólo se ha violado una norma parental, sino también la relación transaccional que rige las relaciones de los hombres con su medio ambiente [...], produciéndose así una doble transgresión. Esto evidencia que las normas que regulan la sociedad con su medio, son de la misma naturaleza que las que regulan las relaciones parentales, estando ambas estructuradas en torno al mismo principio de reciprocidad (Bartolomé y Barabás, 1996: 283).
Similar violación de la norma de este principio aparece en otro relato, en el cual la Gran Culebra - que es la Dueña de los Peces - devora a una mujer por desperdiciar muchos camarones haciendo regalos a vecinos y amigos, lo cual constituye tanto "la violación de una norma ecológica [como] la violación de las normas de reciprocidad generalizada que deben existir a nivel del grupo doméstico, ya que las relaciones comunitarias deben estar asignadas por la reciprocidad equilibrada" (Bartolomé y Barabás, 1996: 284).

Después de esta exposición, creo haber mostrado un aspecto cultural cuya gran relevancia para la ética ambiental queda manifestada por el papel regulador que ejerce en lo que podríamos denominar el manejo de los recursos. Dicho esto, podemos pasar al siguiente aspecto.

\section{Lugar del ser humano en el mundo}

La cultura occidental separa claramente a los seres humanos del resto del mundo natural, un dualismo que ha sido criticado por diversos autores contemporáneos. Merece la pena recordar las ya clásicas críticas de White (2007) a la concepción judeocristiana del mundo por el hecho de que pone al ser humano por encima de toda la creación, otorgándole dominio sobre todo lo que existe. Sin embargo, en otras culturas este dualismo no es tan marcado, al existir límites imprecisos entre ambas esferas ontológicas o, incluso, llega a ser inexistente. Aquí presentaré dos aspectos relativos a esta cuestión del lugar que el ser humano ocupa en el cosmos, como son las genealogías y el papel que cada etnia otorga a los animales no humanos.

Las genealogías que vinculan a los seres humanos con sus orígenes son especialmente interesantes para la ética ambiental puesto que generan continuidades entre la vida humana y la no humana. Esto se entenderá mejor observando un ejemplo muy conocido dentro de la disciplina, el Kumulipo, poema en el que los hawaianos plasmaron toda la mitología relativa a su creación, incluyendo además la genealogía de sus reyes. Según Callicott (1994: 110), quien recoge la opinión del traductor de este canto al inglés, el Kumulipo propone un 
recuento de los orígenes de la vida en el planeta de signo evolucionista, "asombrosamente similar al de la biología actual". La importancia que tal evolucionismo posee para la ética ambiental radica en que éste a menudo lleva implícito un "sentido de la relación, del parentesco, entre la vida humana y no humana" (Callicott, 1994: 111). Así, pues, las genealogías serían susceptibles de ubicar a los seres humanos en un plano de relativa igualdad con el mundo no-humano. ${ }^{3}$

En Oaxaca encontramos también interesantes genealogías, entre las cuales destaca la de los mixtecos. Mindek nos explica que la nobleza que gobernó la Mixteca durante la época prehispánica, especialmente la que levantó las ciudades y centros ceremoniales a partir del año 500 a.n.e., se consideraba emparentada entre sí, lo cual condujo a estrictas normas sociales con respecto, por ejemplo, a los matrimonios, que sólo podían darse entre nobles. Los nobles mixtecos se consideraban a sí mismos "descendientes de los primeros mixtecos, que se desprendieron de un árbol localizado a orillas del Yutsa to'on ('Río de los linajes') ubicado en el pueblo de Apoala" (Mindek, 2003: 10, énfasis añadido), evento para presidir el cual los dioses enviaron al propio Quetzalcóatl, según explica el Códice Vindobonensis. Este mito fundacional, que se remonta a la época prehispánica, conserva hoy día un importante papel en el establecimiento de la identidad mixteca, pues "todos los mixtecos participan del mismo mito de origen, lo cual es la mejor prueba de un pasado común y compartido" (Mindek, 2003: 14).

En el caso de los mazatecos, encontramos una situación muy semejante: los nueve soberanos que gobernaron durante el primer señorío, de 1170 a 1300 d.n.e., se considera que pertenecían a "una misma familia, que nació, según la tradición oral, de unos troncos de árbol" (Luna, 2007: 15). Esta tradición es perfectamente coherente con la gran relevancia que tienen los árboles en la cosmogonía mazateca, en la cual se encuentran sacralizados. Así, por ejemplo, todo

[...] el territorio mazateco está delimitado por árboles sacralizados. En la cima del Cerro de la Adoración se ubica un árbol sagrado también llamado por los mazatecos 'el ombligo del mundo'. En la parte baja está la pochota sagrada, puerta de entrada a la Mazateca baja y la Chinantla. Estos árboles sacralizados son elementos muy importantes para la cosmogonía mazateca (Luna, 2007: 12)

Otro aspecto de interés para la ética ambiental es el papel otorgado por las diferentes culturas a los animales no-humanos. Para tenerlo presente, a manera de contraste, debemos recordar cómo la cultura occidental considera a muchos animales no-humanos prácticamente como objetos, sin otro valor que el instrumental (Singer, 1999; Regan, 2006). Las etnias oaxaqueñas no comparten esta concepción de los animales, como mostraré en las líneas que siguen, comenzando por los huaves, cuya cosmovisión sacraliza y resignifica a algunas de las diferentes especies de animales existentes en el Istmo de Tehuantepec a través de la idea del tonalismo ${ }^{4}$ (Tranfo, 1979). La primera de tales especies es el lagarto (júm), considerado tona de un tipo particular de mujeres, aquellas que según la leyenda poseen una vagina dentada. En efecto, la tradición oral de los huaves menciona en numerosas ocasiones esta característica de las mujeres cuya tona es el lagarto, la cual las hacía extremadamente peligrosas, en especial cuando se casaban con jóvenes inexpertos. Según Millán (2011), el lagarto funciona como lo que Lévi-Strauss (2000: 485-506) denominaba "operadores binarios", es decir, mecanismos del pensamiento mítico que permiten ordenar la experiencia del mundo y de la propia existencia de acuerdo con oposiciones. En este caso, el lagarto se liga por una parte con la serpiente (ndiüc), una entidad ambigua carente de sexo y, por ende, según la mitología mareña, de un lugar en el espacio, pero, sobre todo, terriblemente destructiva al hallarse vinculada con las inundaciones, tan frecuentes en el área. Por otra parte, el lagarto también se liga con un ser mitológico denominado Sapcheeb. Esta figura, generalmente una joven decapitada que seduce a los pescadores y los castra con su vagina dentada, se forma con las primeras gotas de lluvia que caen en los meses calurosos, las cuales se evaporan enseguida. Según Lupo (1993), Sapcheeb representa el lado maligno de la 
tierra, su voracidad, al nacer de una transgresión —en concreto, de unas lluvias que todavía no deberían haber aparecido-.

Otro animal destacado por la cosmovisión huave es la tortuga de tierra (pój). Este animal, que suele nacer al final de la temporada de lluvias, es tan importante para el simbolismo de los huaves que su ciclo vital se identifica con todo un ciclo ceremonial, iniciado con la fiesta de la Cruz Verde del mar Tileme - el cuarto viernes de Cuaresma- y finalizado con la mayordomía del día de Corpus Christi. La víspera de esta jornada se realiza un recorrido durante el cual la tortuga va siendo presentada por las casas de la comunidad, simbolizando el modo en que la misma pasa de ser huérfana a encontrar unos padres, y hasta unos padrinos, quienes finalizarán el recorrido presentándola ante el altar del mayordomo; un recorrido que Millán y García (2003: 106) caracterizan adecuadamente como un tránsito "de la naturaleza a la cultura". La tortuga, a diferencia de la serpiente, es un animal domesticado, socializado, capaz de vivir junto a los seres humanos; por ello, el agua producida por la tortuga es cálida y jamás se descontrola. Los huaves denominan a este líquido achel poj (orina de tortuga) y lo identifican con la llovizna que precede a las lluvias. Si comparamos esta llovizna con las lluvias torrenciales causantes de las inundaciones, entenderemos claramente la diferencia entre la tortuga domesticada y la salvaje serpiente, que atenta contra el orden natural.

Los mixes, como muchas otras etnias oaxaqueñas, consideran que todas las personas nacen acompañadas de un alter ego (tso'ok) que llevará una vida paralela a la de aquéllas. Las características de este alter ego se conocen a través del calendario. En principio, puede ser fuertebueno, como es el propio de los curanderos, fuerte-malo, como el de los brujos, o débil, para las demás personas. Ciertos individuos, por su parte, tienen como alter ego a animales o fenómenos que les confieren respeto por parte de los demás, caso del trueno, el rayo, el jaguar o la serpiente. Tal sucede con el rey Kontoy, un personaje decisivo tanto para la mitología mixe como para su vida ritual. Sería interesante narrar aquí toda su historia, pero, a efectos de esta exposición, lo más interesante es reparar en que, según se cuenta, este rey tenía a una serpiente como hermana, la cual Torres (2004: 29) sugiere que podría entenderse como el nahual del rey. Al ser bendecida por primera vez, tal serpiente se habría quedado petrificada, convirtiéndose en lo que hoy día conocemos como las cascadas de Hierve el Agua.

La concepciones de los mixes sobre psicología parecen ser coherentes con la idea del tonalismo, pues consideran que el individuo posee diversas almas, en un número variable, generalmente entre tres y siete, aunque en algunos casos alcanza la cifra de catorce (Lipp, 1998). Una de ellas es el alma que se identifica con el concepto cristiano de alma, mientras que las demás se corresponden con espíritus de la religión mixe. La más importante es el alma del estómago; otras, como la de la sangre o el hígado, pueden salir del cuerpo al dormir. También existen dos almas que se ubican sobre los hombros, una de las cuales, dotada de alas de águila, es buena y, la otra, con alas de murciélago, es no-buena. Además, existe una especie de alma guardiana y, muy destacadamente, "una vida paralela, que se manifiesta en forma de animal [...] o de fenómeno meteorológico" (Torres, 2004: 10).

La presencia del nahualismo y el tonalismo en las cosmovisiones de los pueblos originarios oaxaqueños no se agota con las referencias mencionadas; por el contrario, se halla extendida en prácticamente todos los grupos, así como también en poblaciones afrodescendientes y mestizas. Sin embargo, no es necesario seguir buscando ejemplos. Lo citado hasta ahora es suficiente para hacer notar un marcado contraste entre la relativamente simple concepción occidental y la de estas etnias, que es mucho más compleja.

Para mostrar otro modo de entender el papel otorgado a los animales no humanos, presentaré únicamente el modo en que algunas etnias oaxaqueñas se refieren a los perros. Para los mixes, se debe tratar bien a los perros negros, porque un perro negro es quien ayuda a las almas a cruzar al mundo de los muertos $y$, si se trata mal a los perros durante la vida, éstos no nos ayudarán en el momento de la muerte. ${ }^{5}$ Los mazatecos también consideran que un perro negro 
habrá de ayudar a los difuntos a pasar al otro mundo (Suaste, 1998: 283). Del mismo modo, los chinantecos consideran a los perros como psicopompos, pues las almas de los muertos deben cruzar un río en su camino al otro mundo, tarea en la que son auxiliados por un perro. Además, los perros cumplen para esta etnia un papel protector: cuando un perro se sacude, en realidad está cerrando el paso a los nahuales, que deben contar todos los pelos que se le han caído al perro antes de atacar a su dueño. Ideas similares aparecen también en la cosmovisión de los antiguos zapotecos; éstos, afirma Cruz, "rendían especial reverencia al Beco-Xolo [...] perro pelado de rala vellosidad leonada que no era otro que el xoloitzcuintli mexica y que el arte vernáculo de la región tehuantepecana ha recordado en el gracioso son bailable bicu bedeh mexu o 'Son del perro güero y sarnoso"' (2002: 191). El mismo Cruz, refiriéndose a los mixes, retoma la idea de que el perro negro defiende la casa de los espíritus:

El perro negro es un defensor decidido del hogar, ante los vivos y los muertos. Cuando alguien sucumbe, el perro negro se coloca en la puerta de la casa mortuoria e impide que el alma en pena del difunto vuelva a aquélla para encontrar a los vivos; el alma suplica entonces al guardián que le permita el paso a su antiguo hogar, y el perro negro para entretenerla le dice que le dejará entrar en la choza bajo condición de que le cuente todos los pelos de su cuerpo. El alma empieza a contárselos uno a uno y cuando el perro comprende que ya va a terminar aquella su faena, se sacude con violencia; el alma pierde la cuenta y comienza de nuevo la operación; así repetidas veces ocurre esto hasta que la sombra fúnebre se fastidia y se va (Cruz, 2002: 279).

En cuanto a la influencia que estas concepciones tienen sobre el comportamiento, reproduciré un relato de la tradición mixteca citado por González:

[...] el perro negro tiene un significado especial, ya que nuestros abuelos platican que a este animal no se le debe golpear, ni dejarlo amarrado bajo la lluvia cuando cuide la milpa en el monte, porque si se le hace daño, cuando el perro y la persona mueran, no ayudará al dueño, o al que lo haya tratado mal, a cruzar el río que existe en el más allá. Porque se cree que en la otra vida existe un río muy grande que la persona que muere deberá cruzar; y si no golpeó al animal, éste estará pendiente esperando al dueño para que suba en su espalda y lo cruce en ese profundo río; ya que como hemos de saber los perros son muy buenos nadadores. Por lo tanto, es mejor cuidar a este animal para que así tengamos su ayuda (González, 2008: 43, cursivas añadidas).

De consideraciones como las mencionadas parece desprenderse una serie de normas éticas muy claramente expresadas, y tal situación nos abre a interesantes cuestiones que introduciré a continuación.

\section{Reflexiones finales}

¿Quégana laética ambiental al estudiar este repertorio de consideraciones propias de los pueblos originarios que moran en el estado de Oaxaca? Creo que, si observamos el contenido del artículo desde las perspectivas éticas mostradas al inicio, la respuesta es prácticamente obvia. Cualquiera de estas concepciones propias de la diversidad cultural oaxaqueña, y algunas otras que se podrían presentar —en particular la sacralización de los espacios-, aporta ideas susceptibles de renovar el pensamiento ambiental, al incidir directamente sobre debates que están vivos en el área.

Un conocido texto de Inglehart (1995) propone que sólo las naciones desarrolladas, con prosperidad económica y cuyos habitantes experimentan un cambio generacional hacia la adopción de valores "postmaterialistas", son capaces de generar actitudes de protección y respeto al medioambiente; del mismo modo, los habitantes de las naciones escasamente desarrolladas son menos proclives a preocuparse por los problemas ambientales y a presentar comportamientos a favor del ambiente. Desde su publicación, esta tesis ha enfrentado numerosas críticas, así como diversos resultados que se le oponen (Dunlap y Mertig, 1995; Mostafa, 2013; Knight y Messer, 2012). Stern et al. 
aplican al estudio del movimiento ambientalista su conocida teoría valor-creencia-norma, según la cual "las acciones basadas en normas se derivan de tres factores: aceptación de valores personales particulares, creencias de que hay cosas importantes para esos valores que se encuentran bajo amenaza, y creencias de que las acciones iniciadas por el individuo pueden contribuir a paliar la amenaza y restaurar los valores" (Stern et al., 1999: 83). Por ejemplo, estos mismos autores hallan que quienes tienen por sagrada a la naturaleza, bien porque la consideren una creación de Dios, bien porque tal sacralidad surja de sí misma, "apoyan más activamente la protección ambiental” (Stern et al., 1999: 86), sin que los valores postmaterialistas tengan relevancia en la consecución de este apoyo.

Estudiar las concepciones de las diferentes etnias oaxaqueñas, como se ha hecho en este artículo, podría apoyar las consideraciones de Stern, aportando así nuevos ángulos al debate, teniendo en cuenta que los diferentes grupos etnolingüísticos de Oaxaca distan mucho de ajustarse a la descripción de las sociedades postmaterialistas pero, en cambio, muestran comportamientos que se pueden considerar muy cercanos al ambientalismo. Su estudio puede sugerirnos también que, quizás, abordar las concepciones de ética ambiental desde una perspectiva centrada en el Estado-nación, tal y como hacen los estudios citados, haya dejado fuera aspectos importantes que surgen precisamente al adoptar un punto de vista que tome en cuenta las variaciones étnicas.

El pragmatismo ambiental, recordaré, se pone como meta encontrar argumentos capaces de influir en las políticas públicas y, más aún, en el pensamiento y la conducta de la gente. Una vez más, quisiera preguntarme por el papel que pueden jugar consideraciones como las citadas en la persecución de este objetivo. Si es cierto que, como tantas veces ha afirmado verosímilmente Rorty (1991; 1996: 169-171; 2000: 246-250), las sociedades evolucionan moralmente a través de un cambio cultural que involucra la aparición y posterior literalización de metáforas, la búsqueda de nuevas metáforas debería ser un elemento destacado de cualquier ética ambiental. Al respecto, creo que una educación ambiental enfocada en tal búsqueda debería ser uno de los puntos clave de esa evolución. Sin entrar demasiado en el tema, no creo, desde luego, que se trate de que todo el mundo se "convierta" a las cosmovisiones originarias, lo cual sería inviable y hasta cierto punto contradictorio.

Se trata más bien de poner a dialogar nuestras concepciones con dichas cosmovisiones, pero, y es un pero muy importante, en un plano de absoluta igualdad. De entrada, el simple hecho de mostrar el modo en que las cosmovisiones de estas etnias les han ayudado a vivir en un estado de relativa armonía con el medioambiente, un estado que es compatible con las propuestas actuales en la órbita del desarrollo sustentable - y en muchos casos las supera en profundidad, entendido el término en el sentido de Naess (1973) - , les otorga, a mi entender, un valor innegable como casos paradigmáticos. Esos resultados devengados por sus cosmovisiones, así como lo que el pragmatismo denominaría "las consecuencias prácticas” de sus epistemologías, convierten a los pueblos originarios no sólo en interlocutores válidos, sino también en impresionantes maestros. Asimismo, dado que muchos problemas ambientales exigen un tratamiento a nivel local, las cosmovisiones de las etnias que habiten esas comunidades locales deben ser tenidas en cuenta cuando se planee dicho tratamiento, existiendo ya numerosos ejemplos que muestran con claridad tanto las ventajas de las epistemologías y prácticas locales, como los beneficios de actuar integrando las aportaciones de las mismas (Gadgil et al., 1993; Carbonell et al., 2001; Berkes, 2008; Sobrevila, 2008).

A lo largo de este texto he tratado de sugerir las bases para el establecimiento de una cooperación más estrecha entre los estudios oaxaqueños y la ética ambiental, una cooperación en la cual ambas partes salgan fortalecidas. Un resultado de esta cooperación puede ser, esperamos, el pleno reconocimiento de las etnias originarias como interlocutores válidos con la ciencia, y en general con el pensamiento occidental. Este reconocimiento de su plena igualdad a nivel dialógico es todavía, hoy por hoy, una asignatura pendiente en muchos países, incluido México, y creo que buscar ideas para incrementar el pluralismo en ética ambiental 
proporciona otra razón más para estudiar, defender $y$, en aquellos casos en que sea necesario, rescatar las culturas y cosmovisiones de los pueblos originarios. De otro modo, seguiremos marginando a grupos de los que tanto podemos aprender.

\section{Notas}

${ }^{1}$ Las tres formas restantes serían: a) buscar vínculos entre el pensamiento de los autores pragmatistas clásicos, como Peirce o Dewey, y los problemas ambientales del mundo contemporáneo; b) diseñar estrategias susceptibles de lograr una comunicación más efectiva entre los activistas, los académicos, los diseñadores de políticas y el público, y c) investigar los fundamentos teóricos de las diversas organizaciones ambientalistas, en busca de puntos de acuerdo que permitan llegar a elecciones políticas concretas.

2 "La gran diversidad cultural de Oaxaca se evidencia en el reconocimiento en la legislación estatal de los siguientes pueblos indígenas: Amuzgo, Cuicateco, Chatino, Chinanteco, Chocholteco, Chontal, Huave, Ixcateco, Mazateco, Mixe, Mixteco, Náhuatl, Triqui, Zapoteco y Zoque" (GEO, 2011: 67).

3 También, aunque sería más bien una hipótesis por explorar, pueden considerarse como generadoras de un cierto ideal de respeto, vía la continuidad o relativa igualdad que establecen con el mundo no-humano.

4 Saltándonos por el momento las múltiples particularidades con que los diferentes grupos ornan este fenómeno, la idea básica que opera este complejo cultural es que las personas nacen acompañadas de un alter ego, generalmente un animal - aunque también puede ser algún elemento natural, como el rayo-, que influye de manera decisiva en el propio curso de su vida, y también en la percepción que de la persona tienen los demás miembros de la sociedad. El tonalismo se relaciona con el nahualismo (ver, por ejemplo, López, 1980), según el cual algunas personas son capaces de transformarse a voluntad en animales.

${ }^{5}$ Los mixes cuentan una historia, relacionada con el diluvio que precedió a la creación de este mundo, según la cual un hombre se quedó con su perra, pero cuando el hombre se iba, la perra se transformaba en mujer, quitándose la piel. Dice la leyenda que la perra le hacía tortillas para comer, hasta que éste la espió y descubrió que quien le hacía las tortillas era su perra. Al ser descubierta, la mujer-perra murió de tristeza.

\section{Referencias bibliográficas}

Bartolomé, Miguel A. y Alicia Barabás (1996). Tierra de la palabra. Historia y etnografía de los chatinos de Oaxaca. México: Instituto Oaxaqueño de las Culturas, Instituto Nacional de Antropología e Historia, Fondo Nacional para la Cultura y las Artes.

Bartolomé, Miguel A., Alicia Barabás, Pedro Hernández y Bartola Morales (1999). "Gente de una misma palabra (dzaaa jmiih o tsa jujmi). El grupo etnolingüístico chinanteco". En Alicia Barabás y Miguel A. Bartolomé (ed.), Configuraciones étnicas en Oaxaca. Perspectivas etnográficas para las autonomías. Vol. II: Mesoetnias. México: Instituto Nacional de Antropología e Historia-Instituto Nacional Indigenista, pp. 57-93.

Berkes, Fikret (2008). Sacred Ecology: Traditional Ecological Knowledge and Management Systems. Filadelfia y Londres: Taylor and Francis.

Brockmann, Andreas (2004). La pesca indígena en México. México: Universidad Nacional Autónoma de México.

Callicott, J. Baird (1994). Earth's Insights. A Multicultural Survey of Ecological Ethics from the Mediterranean Basin to the Australian Outback. Berkeley y Los Angeles: University of California Press.

Carbonell, Montserrat, Nadra Nathai-Gyan y C. Max Finlayson (ed.) (2001). Science and Local Communities: StrengtheningPartnerships for EffectiveWetlandManagement. Memphis, TN: Ducks Unlimited Inc.

Carson, Rachel (2010). Primavera silenciosa. Barcelona: Crítica.

Cruz, Wilfrido C. (2002). Oaxaca recóndita. Razas, idiomas, costumbres, leyendas y tradiciones del estado de Oaxaca. Oaxaca: Instituto Estatal de Educación Pública de Oaxaca.

Dunlap, Riley E.y Angela G. Mertig(1995). “GlobalConcern for the Environment. Is Affluence a Prerequisite?" En Journal of Social Issues, vol. 5l, núm. 4, pp. 121-138. 
Gadgil, Madhav, Fikret Berkes y Carl Folke (1993). "Indigenous Knowledgefor BiodiversityConservation". En Ambio, vol. 22, núm. 2/3, pp. 151-156.

Glacken, Clarence J. (1967). Traces on the Rodhian Shore. Nature and Culture in Western Thought from Ancient Times to the End of the Eighteenth Century. Berkeley: University of California Press.

Gobierno del Estado de Oaxaca (2011). Plan Estatal de Desarrollo de Oaxaca 2011-2016. Oaxaca: Gobierno del Estado.

González López, Andrés (2008). ChachitoñiviÑuu Chikua'a. Creencias de Jicayán. México: Comisión Nacional para la Cultura y las Artes, Secretaría de Cultura, Gobierno de Oaxaca, Fundación Alfredo Harp Helú.

Inglehart, Ronald (1995). "Public Support for Environmental Protection: Objective Problems and Subjective Values in 43 Societies". En Political Science and Politics, núm. 15, pp. 57-71.

Knight, Kyle W. y Benjamin W. Messer (2012). "Environmental Concern in Cross-National Perspective: The Effects of Affluence, Environmental Degradation, and World Society". En Social Science Quarterly, vol. 93, núm. 2, junio, pp. 521-537.

Light, Andrew (2003). "Restauración ecológica y la cultura de la naturaleza: una perspectiva pragmática”. En Teresa Kwiatowska y Jorge Issa, Los caminos de la ética ambiental, vol. II. México: Plaza y Valdés, pp. 247-270.

Light, Andrew y Eric Katz (ed.) (1996a). Environmental Pragmatism. Londres y Nueva York: Routledge.

Light, Andrew y Eric Katz (1996b). "Introduction. Environmental pragmatism and environmental ethics as contested terrain". En Andrew Light y Eric Katz (ed.), Environmental Pragmatism. Londres y Nueva York: Routledge, pp. 1-18.

Light, Andrew y Erin McKenna (2004). "Introduction: Pragmatism and the future of human-nonhuman relationships". En Andrew Light y Erin McKenna (ed.), Animal Pragmatism. Rethinking human-nonhuman relationships. Bloomington, Estados Unidos: Indiana University Press, pp. 1-16.

Lipp, Frank J. (1998). The mixe of Oaxaca. Religion, ritual and healing. Austin, Texas: University of Texas Press.
Lizama Quijano, Jesús (1999). "Los moradores de la tierra del canto. El grupo etnolingüístico cuicateco". En Alicia Barabás y Miguel A. Bartolomé, Configuraciones étnicas en Oaxaca. Perspectivas etnográficas para las autonomías. Vol. II: Mesoetnias. México: Instituto Nacional de Antropología e Historia, Instituto Nacional Indigenista, pp. 295-327.

López Austin, Alfredo (1980). Cuerpo humano e ideología. México: Universidad Nacional Autónoma de México. Luna Ruiz, Xicohténcatl (2007). Mazatecos. México: Comisión Nacional para el Desarrollo de los Pueblos Indígenas.

Millán Valenzuela, Saúl (2003). Huaves. México: Comisión Nacional para el Desarrollo de los Pueblos Indígenas, Programa de las Naciones Unidas para el Desarrollo.

Millán Valenzuela, Saúl (2011). "Pueblos indígenas de México: los huaves, representantes de una cultura lagunar". En Atlas de culturas del agua en América Latina y el Caribe. Disponible en: http://www.unesco.org.uy/ ci/fileadmin/phi/aguaycultura/Mexico/06_Huaves. pdf (consultado el 25 de diciembre de 2011).

Millán Valenzuela, Saúl y Paola García Souza (2003). Lagunas del tiempo. Representaciones del agua entre los huaves de San Mateo del Mar. México: Consejo Nacional para la Cultura y las Artes, Instituto Nacional de Antropología e Historia.

Mindek, Dubravka (2003). Mixtecos. México: Comisión Nacional para el Desarrollo de los Pueblos Indígenas. Mostafa, Mohamed M.(2013). "Wealth, Post-materialism and Consumers' Pro-environmental Intentions: A Multilevel Analysis across 25 Nations". En Sustainable Development, núm. 21, pp. 385-399.

Naess, Arne (1973). "The shallow and the deep, longrange ecology movement. A summary”. En Inquiry, vol. 16, núm. 1, pp. 95-100.

Regan, Tom (2006). Jaulas vacías. El desafío de los derechos de los animales. Barcelona: Altarriba.

Rorty, Richard (1991). Contingencia, ironía y solidaridad. Barcelona: Paidós.

Rorty, Richard (1996). Objetividad, relativismo y verdad. Escritos filosóficos l. Barcelona: Paidós.

Rorty, Richard (2000). Verdad y progreso. Escritos filosóficos 3. Barcelona: Paidós. 
Rozzi,Ricardo(2001). “Éticasambientaleslatinoamericanas: raíces y ramas". En Richard Primack, Ricardo Rozzi, Peter Feinsinger, Rodolfo Dirzo y Francisca Massardo, Fundamentos de conservación biológica: perspectivas latinoamericanas. México: Fondo de Cultura Económica, pp. 281-329.

Singer, Peter (1999). Liberación animal. Madrid: Trotta.

Sobrevila Claudia (2008). The Role of Indigenous Peoples in Biodiversity Conservation. Washington: World Bank.

Stern, Paul C., Thomas Dietz, Troy Abel, Gregory A. Guagnano y Linda Kalof (1999). "A Value-BeliefNorm Theory of Support for Social Movements: The
Case of Environmentalism". En Human Ecology Review, vol. 6, núm. 2, pp. 81-97.

Suaste Larrea, René (1998). "Religión, fiestas, mitos y ritos mazatecos". En Iztapalapa, núm. 44, juliodiciembre, pp. 277-286.

Torres Cisneros, Gustavo (2004). Mixes. México: Comisión Nacional para el Desarrollo de los Pueblos Indígenas.

Tranfo, Luigi (1979). "Tono y nagual". En Italo Signorini, Los huaves de San Mateo del Mar. Ideología e instituciones sociales. México: Instituto Nacional Indigenista, pp. 177-213.

White, Lynn Jr. (2007). "Raíces históricas de nuestra crisis ecológica”. En Revista Ambiente y Desarrollo, vol. 23, núm. 1, pp. 78-86. 